\title{
Human-to-human touch in institutional settings : Introduction to the special issue
}

\section{Burdelski, Matthew}

2020

Burdelski , M , Routarinne , S \& Tainio , L 2020 , ' Human-to-human touch in institutional settings : Introduction to the special issue ', Social interaction , vol. 3 , no. 1 . https://doi.org/10.7146/si.v3i1.120247

http://hdl.handle.net/10138/326191

https://doi.org/10.7146/si.v3i1.120247

cc_by_nc_nd

publishedVersion

Downloaded from Helda, University of Helsinki institutional repository.

This is an electronic reprint of the original article.

This reprint may differ from the original in pagination and typographic detail.

Please cite the original version. 
Social Interaction. Video-Based Studies of Human Sociality. 2020 Vol. 3, Issue 1

ISBN: 2446-3620

DOI: $10.7146 /$ si.v3i1.120247

\section{Social Interaction \\ Video-Based Studies of Human Sociality}

Human-to-human touch in institutional settings: Introduction to the special issue

Matthew Burdelski', Sara Routarinne'2, and Liisa Tainio ${ }^{3}$

Osaka University ${ }^{1}$, University of Turku², University of Helsinki 


\section{Introduction}

The papers in this special issue focus on a key dimension of social interaction, namely embodied action, by examining human-to-human touch in institutional settings. Over the past two decades, embodiment has become a central focus of attention, as research on social interaction has shifted from a primary focus on talk to a more holistic perspective (e.g., Depperman, 2013; C. Goodwin, 2000; Meyer, Streeck \& Jordan 2017; Mondada, 2016; Streeck, Goodwin \& LeBaron 2011). This research has examined the ways in which participants deploy "multiple semiotic resources" (C. Goodwin 2000: 1490), such as speech, material objects, structure in the environment, and the body - what Mauss (1979 [1934]) referred to as "techniques of the body"-in carrying out and achieving various interactional purposes. Compared to other embodied and multisensorial phenomena (e.g., vocal, visual, and gestural), this research has given less priority to tactile and haptic acts. This lacuna of research has recently begun to be filled in projects (see edited volumes by Cekaite \& Mondada, 2020; Meyer, Streeck \& Jordan 2017) that detail a wide range of settings where humans touch other humans, animals, or material objects. In comparison to these remarkable projects, here we have narrowly focused on human-to-human touch in institutional settings, which we hope allows us to discover and highlight general and specific phenomena among various institutions and languages.

Human-to-human touch (e.g., interpersonal touch) is a fundamental aspect of sociality, first experienced in the womb (Marx \& Nagy, 2017), and then in infancy and childhood and across the lifespan. As the earliest sensory modality to develop (Montagu, 1986), touch has received much attention in various fields, including neuroscience, psychology, and the humanities (e.g., Cascio, Moore \& McGlone, 2019; Hertenstein \& Weiss 2011; Paterson, 2007). Rather than as a private, mental state, touch is viewed as a public, interactional phenomenon. From this perspective, human-to-human touch is deployed for a range of purposes, such as to display emotion, control, compete, and gain attention. It can be desired or avoided, appropriate or inappropriate, pleasant or unpleasant, and public or private; moreover, it can vary in intensity (e.g., soft, hard), duration (e.g., punctual, sustained), and quality (e.g., stroking, tapping, 
holding). Thus, human-to-human touch is a central resource for conveying stances, enacting identities, and performing social actions that are embedded within trajectories of action and webs of human activity. Importantly, touch varies among individuals, situations, institutions, and cultures (e.g., Finnegan 2002).

While human-to-human touch-as a dialogic act that entails touching another and being touched-is invaluable for fostering and maintaining relationships among family members and close acquaintances (e.g., Cekaite, 2015; M. H. Goodwin \& Cekaite, 2018; M. H. Goodwin, 2017), it is also crucial within many institutional settings for carrying out and accomplishing tasks and projects. In such settings, participants organize their conduct with respect to "specific goal orientations that are tied to their institution-relevant identities" (Heritage, 2004: 106). Although research on institutional interaction has traditionally been concerned with the ways that "interactional practices, actions, stances, ideologies, and identities are being enacted in the talk" (Heritage, 2004: 109) (emphasis ours), research has recently begun to address ways in which these dimensions of social context are also enacted through touch in various institutional settings. These settings include preschools (e.g., Cekaite, 2015, 2016; Cekaite \& Kvist Holm, 2017), classrooms (e.g., Burdelski, 2020; Kääntä \& Piirainen-Marsh, 2013; Heinonen, Karvonen \& Tainio, 2020), healthcare (e.g., Merlino, 2020; Nilsson, Ekström \& Majlesi, 2018; Nishizaka, $2007,2011,2016)$, and sports, dance, and other organized physical activities (e.g., Keevallik and Ekström, 2019; Lefebre, 2020; Meyer \& v. Wedelstadt, 2017). While some studies primarily focus on touch, others thread observations on touch throughout their analyses. Thus, there is a need to focus on human-tohuman touch in institutional interaction, while paying attention to talk and other multiple semiotic resources.

The primary goal of this special issue is to advance our understanding of the ways in which human-to-human touch along with other semiotic resources are deployed to carry out and accomplish institutionally organized activities and projects. We aim to shed light on: 
(1) the trajectories in which touch in institutional settings is deployed, including both its sequential features (i.e., prior to and/or following other turns and social actions) and its laminated features (i.e., together with other semiotic resources: talk, gaze, posture, objects);

(2) the social actions performed through touch as well as other semiotic resources and how these actions relate to participant roles and relationships;

(3) the ways in which touch is related to carrying out and accomplishing the goals of the particular institutional settings and activities in which it emerges.

In relation to these aims, we recognize that human-to-human touch is not fixed or static, but dynamic and adaptable to the contingencies of the interaction and the present circumstances. As we write this introduction, over the last couple of months the world has become gripped by what has been characterized as a "once-in-100-year" pandemic: Covid-19. This situation has propelled humanity into a new reality of "physical distancing," and for some "self-isolation," to slow the spread of the disease. Thus, personal space has rapidly become a highly sensitive issue, monitored by individuals and institutions. As Goffman (1971: 31) observed in The territories of self, "It is a central feature of personal space that legitimate claim to it varies greatly according to the accountings available in the setting and that the bases for these will change continuously." While Goffman's insights on personal space invite us to envision a pandemic as a genesis for rapid and dramatic social change (Aaltola, 2012), the current situation also prompts us to ponder whether an analytic focus on human-to-human touch in institutional settings is relevant or even desirable at this time. We think it is, but we also wonder whether some of the observations made in the papers herein will represent a kind of historical record, or whether touch along with the rest of social life will snap back to normal once the pandemic subsides. Only time will tell, but our hope is that what we are experiencing is a "pause," and that appropriate human-to-human touch will find its way back, albeit likely in changed ways, into the core of everyday social life. 


\section{Summary of the papers}

The papers in this special issue utilize multimodal conversation analysis (e.g., C. Goodwin, 2000; Mondada, 2018, 2019; Streeck, Goodwin \& LeBaron, 2011) to probe the use of touch in various institutional settings (childcare, classrooms, dental care, healthcare, massage therapy, photography studios, and professional sports) and languages (Chinese, Danish, English, German, Finnish, Japanese, and Turkish). Recently in this journal, Greco et al. (2019) discussed theoretical and methodological issues in transcribing touch in social interaction in ways that present both challenges and possibilities for analyzing touch in social interaction. Similarily, the papers in this special issue utilize detailed transcriptions of interaction and images (such as frame grabs or line drawings). Some papers provide embedded videos. As the scope is arguably still broad, in the future we hope to see other collaborative efforts that focus on human-to-human touch in specific institutional settings.

The first paper by Lorenza Mondada and Burak Tekin examines professional touch in arranging bodies for poses in professional photography studios in Switzerland and Turkey. They show how touch is achieved by combining touch with vision, or "touch-cum-vision." In this configuration, the photographer first performs a perspectival posture simulating the photographic eye and then manipulates the model's body. This manipulation makes use of a particular trajectory of arms and hands that suits the practical purposes with precision and is recognizable as non-offending but legitimate in the particular moment. The authors show that the combination of professional vision and professional touch enables the photographer to accomplish the task of arranging poses for photography. Their analysis illuminates the ways in which touch is professionally designed and integrated to the specific institutional setting.

In the next paper by Enhua Guo, Julia Katila, and Jürgen Streeck, the setting is pediatric dentistry in China, where the child client may be resistant and fearful. In focusing on touch by the dentist and caregivers that contributes to the child's participation in the dental examination, the authors examine 
various dimensions of touch (e.g., haptic act/tactile act, instrumental/communicative mode, and control/comfort mode). For instance, they show that "instrumental touch" treats the receiving body more-or-less as a manipulable object (e.g., mother pulls on the child's chin and jaw to open her mouth for the examination), whereas "communicative touch" treats the receiving body more-or-less as an autonomous subject (e.g., mother lightly touches a child's shoulder when directing her to sit in the dentist's chair). They suggest that dental examinations are accomplished through distributed agency where professionals and escorting family members orchestrate tactile actions on the child whose body is manipulated. The significance of their study is that they observe a continuum between communicative/instrumental and other dimensions of touch in relation to the child's agency in an institutional setting.

The next three papers focus on affective touch in either childcare (Burdelski) or healthcare (Raia, Goodwin \& Deng; Raudaskoski). Matthew Burdelski examines Japanese preschool teachers' "compassionate touch" in responding to children's distress (e.g., crying) arising from episodes of peer conflict and accidents (e.g., being pushed or bumped by another child). He outlines three phases of teachers' responses to this distress-namely intervention, investigation, and reparatory-focusing on how teachers deploy compassionate touch along with talk and other resources in the intervention and reparatory phases, such as by using their hands to rub or stroke a child's head/forehead or back/side to comfort them. Burdelski's analysis also details children's agency in inviting, aligning, and resisting the teachers' touch, suggesting that episodes involving compassionate touch are a co-constructed activity.

Federica Raia, Marjorie Goodwin, and Mario Deng examine "caring touch" along with diagnostic/medical touch by a US doctor who practices Relational Medicine. Through a single case analysis involving a patient with a terminal illness, their study suggests that there is a fluid boundary and symbiotic relationship between caring and medical/diagnostic touch. For instance, the doctor's squeezing of the patient's hand can be aimed at both purposes, or the doctor's touch on the patient's shoulder and back when engaging in mundane 
conversation can seamlessly glide into his touch of similar body parts when initiating and carrying out the examination. In linking their findings to a framework of Relational Medicine, the authors suggest that caring touch is a key resource in constituting multiple frames of activity and, most remarkably, in assisting the patient and spouse in coping with the disease.

Pirkko Raudaskoski analyzes "amicable touch" and forms of participation during occupational therapy activities in a residential home for patients with acquired brain injury in Denmark. She shows how staff members and researchers initiated amicable touch, which often included gentle strokes on the arm and quick taps on the shoulder of residents during verbal teasing. She also shows how one of the male residents initiated such touches to another resident, and argues that partly because of these amicable and at times teasing touches the resident's agency, or "how-ability," in which he enacted the role of a caregiver could be considered different compared to other residents.

Raudaskoski's analysis suggests a complex interrelationship between touch, participation, affect, and agency in this institutional setting.

The next two papers (Nishizaka, Kuroshima) focus on touch in Japanese healthcare. Aug Nishizaka focuses on touch, vision, and talk during a midwife's fetal examination of a pregnant woman. Through a single case study, he examines how the midwife's talk along with her touching and pressing with her hands and fingers on the pregnant woman's abdomen helps organize the participants' perception of the shape and location of the fetal body parts (e.g., head, feet, back). He also details how the pregnant woman is an active participant in the session, such as by requesting confirmation and touching her own abdomen. Nishizaka's analysis highlights ways in which touch is a key embodied resource in the interactional construction of multimodal perception, including how participants see and feel in relation to the focus of their immediate attention and scrutiny in this institutional interaction.

Satomi Kuroshima examines touch in medical massage sessions. Through an analysis of several cases, she shows ways in which therapists convey their tactile perception and ways in which patients convey their prior and current sensations of the physical problem (i.e., aches or pains in body parts). 
She shows how therapists sequentially come to an understanding of the patients' problems through the patients' verbal reports prior to and during the massage; through their own tactile inspection (pressing with hands and fingers) of the patients' body parts; and through verbal exchanges with the patient (or the patient's family members), such as by confirming the patient's reported problems and making assessments on the stiffness. Kuroshima's analysis suggests ways in which therapists' touch is linked to different accountabilities, responsibilities, and rights of knowing and perceiving in this institutional setting.

The next two papers focus on touch in classrooms in Finland. In the first paper, Sara Routarinne, Pilvi Heinonen, Ulla Karvonen, Liisa Tainio, and Maria Ahlholm focus on touch in achieving a focal point within pedagogical tasks in primary classrooms. They examine action sequences where a pedagogical activity is underway and a participant is not attending to the relevant pedagogical content. In these sequential contexts, a light touch is used as a summons followed by a deictic pointing gesture accompanied by talk and adjustment of bodies forming a "complex multimodal gestalt" (CMG). They show how the CMG occurs between teachers and students and can be initiated by either one, though more typically by the teacher. Their analysis shows how the CMG affords non-competing parallel participation frameworks in classroom interaction and how it provides a technique for accomplishing pedagogical goals.

The second paper on classrooms by Teppo Jakonen and Kreeta Niemi explores touching among peers in a digitally rich primary school. They examine tactile practices in small groups where the activity is to animate a story using a shared iPad tablet. They find a frequent practice where one participant (who is currently in possession of the tablet) blocks another participant's incoming hand moving towards the tablet with their own hand or body. This blocking is used as a means of negotiating and claiming a turn while keeping possession of the tablet. They show that touch as blocking is treated as a morally and socially problematic action. As digital devices are increasingly being employed in peer collaborative classroom activities, their results provide insight for designing and putting new digital pedagogies to use in educational settings. 
The final paper by Christian Meyer and Ulrich v. Wedelstaedt analyzes touch in professional sports, focusing on tactile practices before and during a handball game in Germany. As their starting point, they draw upon Canetti's (1978 [1960]) framework of how the general avoidance of touch and fear of being touched by others in public becomes reversed in certain situations, such as when we are in a large crowd of people (who may be pushed up against each other, such as on a subway). Specifically, they show how the touching practices between handball team members developed from avoiding touch in the locker room before the game, to careful touch while attuning to the game, and finally to systematic, heightened and even hard touch between players in ways that established a "team body" that entered the game field and was able to play as a successful unit. The study sheds light on the transformation and change of touch among group members across time and space.

In concluding this special issue, Asta Cekaite provides a commentary by outlining the theoretical background on touch, summarizing the main themes in this research, making connections between the papers, and pointing out avenues for future research.

\section{Acknowledgements}

This special issue evolved out of a panel organized by Asta Cekaite and Christian Meyer at the 2017 International Pragmatics Association (IPrA) conference in Belfast, titled "Touch in social interaction: Integrating haptics into embodied interaction research." We want to thank the panel organizers for inviting the three of us to participate, and the presenters, attendees, and especially Chuck Goodwin for his incisive commentary. We also want to express appreciation to all of the contributors, and the reviewers of the papers and the journal editors for their suggestions.

\section{References}

Aaltola, M. (2012). Understanding the politics of pandemic scares: An introduction to global politosomatics. London and New York: Routledge. 
Burdelski, M. J. (2020). Embodiment, ritual, and ideology in a Japanese-as-aheritage language preschool classroom. In M. J. Burdelski \& K. M. Howard (eds.), Language socialization in classrooms: Culture, interaction, and language development (pp. 200-223). Cambridge: Cambridge University Press.

Canetti, E. (1978 [1960]). Crowds and power. Translated by C. Stewart. New York: Continuum.

Cascio, C. J., Moore, D. \& McGlone, F. (2019). Social touch and human development. Developmental Cognitive Neuroscience, 35, 5-11.

Cekaite, A. (2015.) The coordination of talk and touch in adults' directives to children: Touch and social control. Research on language and social interaction, 48(2), 152-175.

Cekaite, A. (2016). Touch as social control: Haptic organization of attention in adult-child interactions. Journal of Pragmatics, 92, 30-42.

Cekaite, A. \& Kvist Holm, M. (2017). The comforting touch: Tactile intimacy and talk in managing children's distress. Research on Language and Social Interaction, 50(2), 109-127.

Cekaite, A. \& Mondada, L. (eds.) (2020). Touch in social interaction: Touch, language and body. London and New York: Routledge.

Depperman, A. (2013). Multimodal interaction from a conversation analytic perspective. Journal of Pragmatics, 46(1), 1-7.

Finnegan, R. (2002). Communicating: The multiple modes of human interconnection. London: Routledge.

Goffman, E. (1971). The territories of self. In E. Goffman Relations in public: Microstudies of the Public Order (pp. 28-61). New York: Harper \& Row, Publishers,

Goodwin, C. (2000). Action and embodiment within situated human interaction. Journal of Pragmatics, 32(10), 1489-1522.

Goodwin, M. H. (2017). Haptic sociality. The embodied interactive constitution of intimacy through touch. In C. Meyer, J. Streeck \& J. S. Jordan (eds.) Intercorporeality: Emerging Socialities in Interaction (pp. 73-102.). New York: Oxford University Press, 
Goodwin, M. H. \& Cekaite A. (2018). Embodied family choreography: practices of control, care, and mundane creativity. New York: Routledge.

Greco, L., Galatolo, R., Horlacher, A. S., Piccoli, V., Ticca, A. C. \& Ursi, B. (2019). Some theoretical and methodological challenges of transcribing touch in talk-in-interaction. Social Interaction: Video-Based Studies of Human Sociality, 2(1).

Heinonen, P., Karvonen, U. \& Tainio, L. (2020). Hand-on-shoulder touch as a resource for constructing a pedagogically relevant participation framework. Linguistics and Education 56. https://doi.org/10.1016/j.linged.2020.100795 Heritage, J. (2004). Conversation analysis and institutional talk. In K. L. Fitch \& R. E. Sanders (eds.) Handbook of Language and Social Interaction (pp. 103-147). Mahwah, NJ: Lawrence Erlbaum.

Hertenstein, M. J. \& Weiss, S. J. (2011). The handbook of touch: Neuroscience, behavioral, and health perspectives. New York: Springer.

Kääntä, L. \& Piirainen-Marsh, A. (2013). Manual guiding in peer-group interaction: A resource for organizing a practical classroom task. Research on Language and Social Interaction, 46(4), 322-343.

Keevallik, L. \& Ekström, A. (2019). How to take the floor as a couple: Turntaking in Lindy Hop jam circles. Visual Anthropology, 32(5), 423-444.

Lefebre, A. (2020). To touch and to be touched: The coordination of touchingwhole-body-movements in Aikido practice. In A. Cekaite \& L. Mondada (eds.), Touch in social interaction: Touch, language and body (pp. 150170). London and New York: Routledge.

Marx, V., \& Nagy, E. (2017). Fetal behavioral responses to the touch of the mother's abdomen: A frame-by-frame analysis. Infant Behavior and Development, 47, 83-91.

Mauss, M. (1979 [1934]). Body techniques. In M. Mauss Sociology and psychology: Essays (pp. 97-123). London: Routledge \& Kegan Paul.

Merlino, S. (2020). Professional touch in speech and language therapy for the treatment of post-stroke aphasia. In A. Cekaite \& L. Mondada (eds.), Touch in social interaction: Touch, language and body (pp. 197-223). London and New York: Routledge- 
Meyer, C., Streeck, J. \& Jordan, J. S. (eds.) (2017). Intercorporeality: Emerging Socialities in Interaction. New York: Oxford University Press

Meyer, C. \& v. Wedelstaedt, U. (eds.) (2017). Moving bodies in interactionInteracting bodies in motion: Intercorporeality, interkinesthesia, and enaction in sports. Amsterdam/Philadelphia: John Benjamins.

Mondada, L. (2016). Challenges of multimodality: Language and the body in social interaction. Journal of Sociolinguistics, 20(3), 336-366.

Mondada, L. (2018). Multiple temporalities of language and body in interaction: Challenges for transcribing multimodality. Research on Language and Social Interaction, 51, 85-106.

Mondada, L. (2019). Contemporary issues in conversation analysis:

Embodiment and materiality, multimodality and multisensoriality in social interaction. Journal of Pragmatics, 145, 47-62.

Montagu, A. (1986). Touching: The human significance of the skin. New York: Perennial Library.

Nilsson, E., Ekström, A., \& Majlesi, A. R. (2018). Speaking for and about a spouse with dementia: A matter of inclusion or exclusion? Discourse Studies, 20(6), 770-791.

Nishizaka, A. (2007). Hand touching hand: Referential practice at a Japanese midwife house. Human Studies, 30(3), 199-217.

Nishizaka, A. (2011). Touch without vision: Referential practice in a nontechnological environment. Journal of Pragmatics, 43, 504-520.

Nishizaka, A. (2016). Syntactical constructions and tactile orientations:

Procedural utterances and procedures in massage therapy. Journal of Pragmatics, 98, 18-35.

Paterson, M. (2007). The senses of touch: Haptics, affects and technologies. Oxford: Berg.

Streeck, J. Goodwin, C. \& LeBaron, C. (eds.) (2011). Embodied interaction: Language and body in the material world. Cambridge: Cambridge University Press. 